\title{
CUESTIONES METODOLÓGICAS EN TORNO A LA INTERPRETACIÓN DE LAS NOVELAS ANTIGUAS COMO MYSTERIENTEXTE (I)
}

\author{
Máximo Brioso Sánchez \\ Universidad de Sevilla \\ mbrioso@us.es
}

\section{METHODOLOGICAL ISSUES ON THE INTERPRETATION OF THE ANCIENT NOVELS AS MYSTERIENTEXTE (I)}

\begin{abstract}
RESUMEN: En la historia de los estudios sobre la novela griega (y romana) se han cometido a veces graves errores metodológicos. Podemos hablar de una filología impresionista en la que el rigor es sustituido sobre todo por la búsqueda de originales y no pocas veces brillantes analogías. En este artículo, dividido en dos secciones, se analiza, con una perspectiva que permite la distancia temporal, el movimiento interpretativo representado por las teorías que vieron en la novela antigua simplemente una colección de Mysterientexte. En esta primera parte se estudia con una perspectiva crítica sobre todo el origen y desarrollo de esta corriente exegética; en la segunda se incide en los puntos más débiles de estas teorías, especialmente en su aplicación a la novela griega y en particular a Longo.
\end{abstract}

PALABRAS CLAVE: Novela antigua, Mysterientexte, teorías, crítica metodológica.

\begin{abstract}
In the history of studies on the Greek (and Roman) novel sometimes serious methodological errors have been committed. We can speak of an impressionist philology in which rigour is replaced mainly by the search for original and often brilliant analogies. This article, divided into two sections, analyzes, with the perspective given by temporal distance, the interpretive movement represented by the theories that viewed the ancient novel simply as a collection of Mysterientexte. In this first part, we study, with a critical view, principally the origin and development of this exegetical stream; in the second, we will be putting special emphasis on the greatest weaknesses of these theories, especially in their application to the Greek romance, and particularly to Longus.
\end{abstract}

KEYWORDS: Ancient novel, Mysterientexte, Theories, Methodological criticism.

RECIBIDO: 15.05.2014. ACEPTADO 28.05.2014 
El pequeño corpus de las novelas griegas que podemos leer completas plantea muchos y lógicos problemas. Están, además de ofrecérsenos en tan corto número, distanciadas en el tiempo, lo que supone que, al ser respuestas literarias a diversos momentos histórico-sociales y culturales, a la vez testimonian una evolución, que puede verse en ciertos aspectos como una maduración del género, pero nos presentan dificultades interpretativas de esa misma evolución. Por ejemplo, el relato de Longo es en bastantes aspectos un caso aislado que contrasta con las demás novelas; sorprende, de otro lado, que Heliodoro, nuestro autor más tardío conocido, retorne en determinadas prácticas a un modelo tan aparentemente poco apropiado como Jenofonte de Éfeso, para lo que hemos de recurrir a alguna justificación que, creemos, es esencialmente ética. Y la esporádica aparición de fragmentos, aunque siempre bendecida, no ha servido para satisfacer nuestro interés de lectores e investigadores, en tanto que el conocimiento, providencialmente complementario, de unos pocos resúmenes bizantinos de obras perdidas no representa sólo una relativa iluminación de rincones oscuros sino a la vez un aumento de la problemática.

Pues bien, si ya este horizonte, del que podríamos señalar aún más dificultades, es complejo y casi más por lo que ignoramos que por lo que sabemos, a él se suman en ocasiones las planteadas por los propios investigadores, por lo que la situación se torna aún más trabajosa de clarificar con los medios con los que contamos. Y advertimos ya desde este momento que nuestro mayor interés en lo que sigue no estará tanto en las materias mismas que iremos revisando, sino sobre todo en la metodología empleada, ya que en las cuestiones que examinaremos resulta asombroso el modo en que ciertos estudiosos han entendido el rigor metodológico y por ello resulta oportuno al menos de vez en cuando denunciar sus carencias.

En la historia del análisis de estos textos hay dos casos famosos por los costes que han representado. Uno es el del dislate cronológico cometido hace ya muchos años y afortunadamente corregido con la aparición de nuevas informaciones, el cual llevó casi a invertir el orden hoy aceptable de las novelas y, consecuentemente, a evidentes confusiones. Hubo falta de información, ciertamente, por lo que no sería justo establecer responsabilidades, pero de tal desorden cronológico se sacaron conclusiones que hoy no pueden sino parecernos disparatadas. A nadie se le ocurriría ya tener, por ejemplo, a Aquiles Tacio por una especie de secuela humorística de Heliodoro, pero de aquellos desvaríos queda alguna huella no fácil de extirpar, y, así, cuando todavía hoy leemos que Aquiles Tacio simplemente practica la "parodia" en alguno de sus novedosos planteamientos novelescos ${ }^{1}$, podemos estar casi seguros de que estamos ante una velada y quizás

\footnotetext{
${ }^{1}$ Cf. como el ejemplo más concentrado de lo que en otros autores no suele pasar de alusiones más o menos aisladas, D. B. Durham, "Parody in Achilles Tatius", CPh 33 (1938) 1-19. Un hecho básico es precisamente que para Durham regía aún la vieja cronología que situaba a Aquiles Tacio después de
} 
inconsciente herencia de aquel viejo dislate. Pero seguramente mucho más grave $\mathrm{y}$, a partir de cierto momento, ya sin el atenuante del error cronológico ha sido la interpretación religiosa del género, que pudo haberse limitado a un razonable subrayado de la fuerte religiosidad, aunque en diversos grados de intensidad y de carácter, que todos podemos observar en él, incluso en aquellas novelas, como la de Caritón, cuya orientación historiográfica creaba un foco de interés que competía con el de la vena piadosa. Nos referimos, por supuesto, a otra cuestión mucho más debatible y que de hecho generó una larga polémica cuyos ecos perduran todavía, la de la interpretación de estos relatos como Mysterientexte. Un debate en el que destacan muy especialmente los nombres de K. Kerényi y R. Merkelbach, que citaremos con frecuencia en las páginas que siguen.

No obstante, no ha sido la primera vez ni el único caso en que se ha tratado de reducir los textos literarios griegos a una servidumbre religiosa tan particular. Se intentó, por ejemplo, con Odiseo y su viaje como un mero reflejo de un proceso iniciático ${ }^{2}$. Y tampoco hubo que esperar al libro de Kerényi de 1927 que luego citaremos para que se aventurase una hipótesis semejante para las novelas, puesto que ya J. Burckhardt en su obra Die Zeit Konstantins des Grossen (reed., Leipzig 1927 -el original es de 1852-, p. 211) expuso la idea de que tanto las $\mathrm{Me}$ tamorfosis de Apuleyo como Antía y Habrócomes de Jenofonte de Éfeso se escribieron para ganar prosélitos para el culto de Isis, lo que a todas luces amenazaba ya con la pretensión de ver en estas novelas (el contagio a las demás era extremadamente fácil) una mera envoltura literaria de las creencias y ritos de las corrientes mistéricas de la época. La expresión de una propuesta semejante, que apenas, que sepamos, tuvo en su momento especial eco ${ }^{3}$, podría haber pasado por una afirmación sin mayor relieve, pero anticipaba la que luego sería una aplicación de una tesis muy parecida y, sobre todo, ya con carácter sistemático a prácticamente todo el género.

Después de la publicación de la ambiciosa obra de E. Rohde Der griechische Roman und seine Verläufer en 1876, en algunos estudiosos quedó un poso de insatisfacción. Rohde había planteado entre otros temas el del oscuro origen del género en Grecia, abriendo una fructífera perspectiva. Pero, además de encuadrar su libro en la vieja cronología, había ofrecido ciertos juicios de valor, por ejemplo sobre un autor como Longo, que requerían un replanteamiento. El tema de los orígenes, en el que no vamos a entrar aquí, fue debatido posteriormente por varios autores, pero sus variadas opiniones tenían en común el estar orientadas

Heliodoro y por tanto al final del desarrollo del género en Grecia. Fue precisamente en 1938 cuando un segundo papiro, publicado por A. Vogliano, confirmó la nueva cronología novelesca.

${ }^{2}$ Cf. una crítica en P. Scarpi, "Il ritorno di Odysseus e la metafora del viaggio iniziatico", en Mélanges P. Lévêque I (Paris 1988) 245-259.

${ }^{3}$ La única cita que hemos encontrado al respecto la leemos en J. G. Griffiths, "Xenophon of Ephesus on Isis and Alexandria", en Hommages à Maarten J. Vermaseren, ed. por M. B. de Boer y T. A. Edridge, vol. I (Leiden 1978) 409-437 (p. 425). 
al descubrimiento de unas fuentes literarias o, en sentido más amplio, culturales. El de la retórica en concreto era un aspecto obligado, como también la vinculación del género, por fechas y por espíritu, con el movimiento de la llamada Segunda Sofística. Pero fue un libro de un estudioso húngaro casi desconocido, Kerényi ${ }^{4}$, el que desvió el tema de los orígenes en una dirección diferente, precisamente la preconizada por Burckhardt bastantes años antes. Nadie puede dudar de que Kerényi, como luego Merkelbach, fueron destacados especialistas en el ámbito de la religiosidad antigua, con especial atención a las influencias orientales. Lo mismo sucede con algunos otros autores que citaremos más adelante, como, por ejemplo, R. E. Witt, y no parece ser un azar que la exposición de estas ideas no provenga del ámbito filológico en el sentido más estricto. Tampoco negaremos que ya Kerényi partió de algunas observaciones razonables, como, sobre todo, de la indiscutible importancia de Egipto en las novelas griegas (no en la de Longo precisamente), incluido un presunto original también griego del texto de Apuleyo, y, por supuesto y como hemos ya señalado, el innegable peso de la religiosidad en ellas, pero de ahí a afirmar, como lo hace, que todas sin excepción son trasuntos en particular de la religiosidad egipcia va un gran trecho. También estaba, en principio, a su favor la tan evidente presencia religiosa en ciertos géneros literarios previos, como, de un modo muy destacado, la épica y la tragedia, que de algún modo reflejaban las creencias de sus tiempos correspondientes. $\mathrm{Y}$, fuese como fuese y como no podía menos de percibirse, la de Kerényi era una respuesta, acertada o no, al debatido tema de los orígenes, con lo que la hipótesis mistérica adquiría unas dimensiones apasionantes por cuanto parecía venir a resolver una importante cuestión aún pendiente.

La posición de Kerényi tenía sus puntos fuertes y sus puntos débiles. El asno de Apuleyo fue un elemento decisivo, puesto que en él no sólo puede sospecharse la vertiente del proselitismo piadoso, sino que la propia iniciación mistérica está reproducida sin tapujos. Estamos ante una obra que sigue ofreciendo una materia inagotable para múltiples aspectos histórico-sociales de su época, pero con una complejidad y una orientación muy alejadas de las de las novelas griegas ${ }^{5}$. Pero, aun así, un estudio como el de E. J. Kenney ${ }^{6}$ ha mostrado que no todas las

${ }^{4}$ Die Griechisch-Orientalische Romanliteratur (Tübingen 1927). La obra de Kerényi fue publicada en buena parte en húngaro, lo que por algún tiempo le restó presencia entre los filólogos occidentales. Lo mismo sucedió con otro estudioso húngaro que mencionaremos después: I. Trencsényi-Waldapfel. Sobre ambos, sus campos de investigación y, en general, la filología en lengua húngara escasamente conocida véase el interesante informe de Z. Ritoók "The contribution of Hungary to international classical scholarship", Hungarian Studies 12.1-2 (1997) 5-15. Una clara dependencia del libro de Kerényi se refleja en las publicaciones posteriores de F. Altheim Literatur und Gesellschaft im ausgehenden Altertum (Halle 1948) y Roman und Dekadenz, ésta última aparecida inicialmente como primera parte de aquélla y luego (Tübingen 1951) ya autónomamente con ese título.

${ }^{5}$ Véase, por ejemplo, la aportación de M. J. Edwards, "The tale of Cupid and Psyche", ZPE 94 (1992) 77-94, que apunta todavía nuevas cuestiones.

6 "Psyche and her mysterious husband", en D. A. Russell (ed.), Antonine literature (Oxford 1990) $175-198$. 
interpretaciones se agotan ni tienen por qué seguir la ruta trazada por Kerényi y Merkelbach, sino que, en concreto, deben tenerse prioritariamente en cuenta las fuentes platónicas. En cuanto a los textos de Jenofonte de Éfeso, Longo y Heliodoro, por no hablar de los de Caritón y Aquiles Tacio, no ofrecían nada semejante, pero el principio de la alegoría, que obliga a una interpretación, abría una fácil puerta a la pretensión de demostrar que, si bien no explícitamente como en Apuleyo $^{7}$, también éstos, sometidos a la conveniente exégesis, eran un testimonio con envoltura literaria de esas doctrinas y rituales que llamamos misterios y en los que el núcleo esencial es la iniciación del mystes. Para Kerényi, sin embargo, no hubo distinción: todas las novelas griegas aportaban datos para esa interpretación. Y, además, el género adquiría así una dignidad propia, muy alejada de las cualidades típicas de simples obras de entretenimiento o de evasión, con un baño de superficialidad, incluso de frivolidad, tal como en algunos momentos la autoridad de Rohde había preconizado en sus juicios sobre un autor como Longo. Y éste mismo era, por el contrario, uno de los soportes decisivos para la hipótesis mistérica.

Pero hay tres cuestiones que siempre deberían recordarse como apoyos básicos y que explican sin duda el que en determinado momento, ya avanzado el siglo XX, surgiese este movimiento. Por ello es conveniente, diríamos prácticamente obligado, que se las tenga en cuenta si queremos apreciar en todo su sentido y valor el origen y despliegue de esta corriente interpretativa. Y es que habían contribuido eficazmente a crear la atmósfera intelectual apropiada para que germinase esta novedosa corriente exegética. La primera corresponde a un fenómeno típico de la tardía religiosidad antigua, pero que hunde sus raíces al menos en el Helenismo: nos referimos al llamado sincretismo, que va unido al de la acusada tendencia que se contempla en la evolución de la religión griega al menos como aproximación hacia el monoteísmo. Pues bien, el sincretismo, innegable en calidad de fenómeno religioso y que permitía no sólo la identificación de las divinidades más dispares y en concreto tanto las de origen helénico como las de procedencia oriental, sino el paso de unas formas de religiosidad a otras en un tiempo en el que proliferaban las sectas, es utilizado por los autores referidos a modo de útil comodín cuando y como conviene, y, por supuesto, conviene siempre. No hay duda ya de que el sincretismo fue un curioso proceso hacia un monoteísmo pagano y de que, con él, cualquier divinidad era a su vez cualquier otra $^{8}$. De modo que en principio la corriente que comentamos tenía vía libre para todo tipo de asociaciones y un amplio panorama donde elegir, y así, Merkelbach

${ }^{7}$ Debe subrayarse que no fue un azar que el primer estudio de Merkelbach en esta línea fuese sobre Apuleyo: "Eros und Psyche", Philologus 102 (1953) 103-116 (está recogido en G. Binder, R. Merkelbach (eds.), Amor und Psyche [Darmstadt 1968] 392-407), donde ya se anticipaba lo más esencial del largo capítulo (pp. 1-90) del libro de 1962 que citaremos.

${ }^{8}$ El ejemplo más claro y accesible se da con Isis en Apuleyo: cf. M. C. Marín Ceballos, "La religión de Isis en 'Las Metamorfosis' de Apuleyo", Habis 4 (1973) 127-179. La autora escribe: "Isis ha llegado a igualarse a casi todas las divinidades egipcias y orientales, así como del mundo grecorromano", 
distingue entre el tipo de las novelas de Dioniso (la de Longo) y las de Isis, las demás, excepto la de Antonio Diógenes, entendida desde una perspectiva pitagórica, muy cercana al mundo mistérico, y la de Heliodoro, nacida del culto (sincrético) de Helios. Así, en Longo, el que Eros sea el dios central como rector del universo parece una novedad sin el respaldo de una tradición, cuando es una idea previa expresada literariamente ${ }^{9}$, pero sobre todo su identificación como Dioniso, defendida tanto por Merkelbach en un artículo ${ }^{10}$ como por H. H. O. Chalk, al que nos referiremos más adelante, pero que no tiene apoyo explícito alguno en el texto. Y ésta es una cuestión metodológica que nos parece muy importante, pero usualmente desdeñada, la de la explicitación o no explicitación en los textos. Puesto que evidentemente no es lo mismo si una idea nos es sugerida, aunque sea del modo más velado, que si somos nosotros los que la imponemos. Por ejemplo, si decimos que Longo tiene ese elevado concepto de Eros como dios universal es, muy en primer lugar, porque él nos lo dice. En cambio, en ningún momento nos habla de esa identificación sincrética entre Eros y Dioniso.

En las novelas griegas, ya en una mera lectura, encontramos la misma diversidad en cuanto a las divinidades invocadas que en los siglos previos. En apariencia, la situación no ha cambiado, pero nada nos asegura que precisamente no estemos ante una simple variedad de nombres que oculten una nueva unidad. Así, ¿estamos seguros de que cuando, en Heliodoro (4.18.6), Teágenes jura sucesivamente por Apolo Pítico, Ártemis, Afrodita y los Érotes, está invocando en realidad a una misma y única divinidad bajo esa diversidad nominal? Una pregunta no fácil de responder, pero que la corriente de pensamiento cuyo centro es la figura de Merkelbach no ha tenido problemas para contestar positivamente. Y de ahí que el tema del sincretismo sea esencial en sus investigaciones sobre la novela greco-romana.

En un artículo sobre la religiosidad en Apolonio de Rodas ${ }^{11}$, del que esperamos se nos disculpe el aprovechamiento aquí en razón de su pertinencia, nos planteábamos ya la pregunta de si éste con su aparato divino (Götterapparat, Göttermaschine, divine machinery) estaba simplemente emulando a Homero, como continuará haciendo todavía siglos después Quinto de Esmirna, o si ya deja entrever algún cambio significativo. Ahí escribíamos lo siguiente: “Apolonio... ha

\footnotetext{
y añade por si hubiera alguna duda: “Tengamos en cuenta que en Apuleyo sólo están atestiguadas algunas de ellas..." (p. 134).

${ }^{9}$ Véase, por ejemplo y para el caso de Longo, la información recogida por W. E. McCulloh (Longus [New York, 1970] en sus páginas 25-55) sobre sus nutridos "components" literarios (platónicos, bucólicos...). También J.-R. Vieillefond en la excelente y nueva edición de Dafnis y Cloe en Les Belles Lettres (Paris 1987) dedica un buen número de páginas al capítulo de "Les sources de Longus" en su prefacio.

10 "Daphnis und Chloe. Roman und Mysterium", Antaios 1 (1959) 47-60. Se trata de un esbozo de lo que será el capítulo correspondiente a Longo (pp. 192-224) en el libro de 1962 que citaremos más adelante. Pero el artículo, falto de notas, carece aún del aparato erudito con que Merkelbach recarga su libro.

11 "El concepto de divinidad en las Argonáuticas de Apolonio de Rodas", en A. López Férez (ed.), Mitos en la literatura griega helenistica e imperial (Madrid 2003) 15-54.
} 
optado por un cierto equilibrio entre la emulación del modelo arcaico y la presión, por velada que aparezca, de la religiosidad posthomérica. Es difícil dudar de que existen aspectos en las Argonáuticas tan radicalmente extrahoméricos o simplemente sólo encubiertos por el lucido ropaje literario que, con la ayuda además de otros indicios, sí nos revelan algo no ya sólo en general sobre la concepción religiosa del tiempo, sino en particular sobre la concepción religiosa que sabemos amparada y fomentada por el poder de las monarquías... ${ }^{12}$. Una concepción cuyo centro es por supuesto la definición del concepto de divinidad, sometido a un progresivo proceso de abstracción ${ }^{13}$, a la vez como providencia, como encarnación del orden moral y como referencia cívica..." (p. 17). Y en ese mismo artículo añadíamos: "Y no nos referimos a que abunden, por ejemplo, los elementos prodigiosos y mágicos, a pesar de que éstos son sin duda un reflejo de la importancia de estos elementos en la religiosidad postclásica. Se ha afirmado al respecto ${ }^{14}$ que el nivel de lo portentoso, entendido como el estrato sobrenatural, es superior aquí al homérico, sobre todo al que se da en la Ilíada... En Apolonio hay un ingrediente mágico, que suplanta simplemente la directa intervención de los dioses como necesidad tradicional por la eficacia de un medium... Y es en las modalidades de la intervención divina donde igualmente podemos rastrear un nuevo concepto de la religión, fuera de la penetración en éste de esa avalancha de influjos mágicos que también reproducen otros textos contemporáneos" (pp. 18 s.). Recordábamos también que "el catálogo de los grandes dioses que participan realmente en el relato es muy parco. Dioses homéricos relevantes han desaparecido de la escena o han pasado a un segundo plano" (p. 32). Y seguíamos: "Si Apolonio se hubiese limitado a reducir la nómina de los dioses activos y a introducir alguna novedad, como la irrupción épica de Eros, apenas nada de importancia se habría alterado en el dominio divino respecto de lo que sucedía en Homero. Pero ésta sería una impresión notablemente superficial y, como veremos, muy alejada de la realidad. Si la institución homérica del aparato divino persiste, la densidad y las modalidades con que ese aparato divino se manifiesta en el texto de las Argonáuticas sí han variado radicalmente, y desde luego el propio comportamiento de los dioses y la distancia y la comunicación entre los ámbitos divino y humano" (pp. 32 s.). Analizábamos después cómo esta evolución, lastrada en la medida lógica por la tradición épica de la que Apolonio dependía, forma parte de un largo proceso con una transformación del mundo divino en el que, en concreto, "Zeus, no hay duda, es... el dios superior y guardián del orden cósmico, identificable ya con el dios de

${ }^{12}$ En nota citábamos, por sus contribuciones recientes, a R. L. Hunter, The Argonautica of Apollonius (Cambridge 1993), especialmente 152-169 y, en ese mismo volumen editado por López Férez, la exposición ("Myth in the service of kings and emperors", pp. 1-14) del Profesor A. S. Hollis.

${ }^{13}$ También en nota recogíamos esta afirmación de D. C. Feeney (The gods in epic: Poets and critics of the classical tradition [Oxford 1991]), que utiliza el término "estrangement": "It is a commonplace that the Olympian gods, however assiduously their cults were mantained, were felt to be more distant from the people of the Hellenistic world than they had been from their ancestors" (p. 80).

${ }^{14}$ De nuevo mencionábamos en nota a Hunter en su libro citado (p. 77). 
los filósofos, de Arato y de Cleantes. Un dios central y supremo, con el que no es concebible que puedan entrar los demás dioses en conflicto" (p. 44). Una transformación en la que es esencial la idea de una armonía tanto en el ámbito de la divinidad como entre dioses y hombres muy alejada de la conflictividad que refleja Homero. Y todo ello relacionado, insistíamos, con esa tendencia al providencialismo como núcleo del concepto divino y que también podemos interpretar como una manifestación premonoteísta. Una tendencia perfectamente acorde, a su vez, con la corriente ya citada y creciente del sincretismo. Conclusiones todas, en fin, emanadas del texto del poema helenístico y no un producto de meras intuiciones. Con lo que el contraste con las doctrinas que examinamos no puede ser mayor.

La segunda cuestión corresponde a un tema de tan fuerte interés antropológico como es el de la iniciación y sus rituales y sin el cual el nacimiento y desarrollo de esa corriente exegética difícilmente pueden explicarse. Y es que a esas propuestas se anticiparon precisamente por unos años los estudios llevados a cabo por especialistas en el tema de la religiosidad antigua sobre los procesos de iniciación ${ }^{15}$. Las dos obras más señaladas al respecto de J. E. Harrison (Prolegomena to the Study of Greek Religion y Themis: A study in the social origins of Greek religion) son respectivamente de 1903 y 1912, un libro muy conocido de G. Dumézil (Le problème des centaures: Étude de mythologie comparée indo-européenne) se publicó en 1929 y el también muy leído de H. Jeanmaire (Couroi et Courètes) en 1939. Y el interés por el tema fue renovado con obras como Le iniziazioni (1960-61) y Paides e parthenoi (1969) de A. Brelich y, es impensable la mera coincidencia, por las mismas fechas en que llega a su cima la exégesis mistérica de la novela antigua. La iniciación está ligada como expresión social a la evolución sexual de los individuos, separando la etapa presexual de otra ya sexualizada, de modo que era fácil trazar un paralelo con los argumentos novelescos en los que suele darse el paso, en los protagonistas, entre una etapa oscura y apenas tocada en el relato, una especie de "prehistoria" (las excepciones están representadas por Longo y Heliodoro), y la ya narrada, que a su vez se inicia con el primer encuentro y el enamoramiento. Si unimos a esto el que en las novelas suele haber divinidades tutelares de este proceso, el círculo se cierra en beneficio de la interpretación de los relatos como una representación literaria del rito de la iniciación. Por otra parte, está la fácil relación entre ésta y los rituales ligados usualmente al concepto de fertilidad, así como los mitos en torno al paso de la vida a la muerte y de la muerte a la vida, una cuestión más correosa de percibir en los textos novelescos pero en cuya ayuda estaban, supuestamente, los casos no infrecuentes en los relatos de falsas muertes (o de amagos de muerte) y, a veces, de portentosas salvaciones. De modo que los entendidos no tenían dificultad alguna para buscar ciertos trasfondos en esa dirección en las novelas, y desde luego ya dijimos que la existencia de un texto como el Asinus de Apuleyo facilitaba la

${ }^{15}$ Tomamos como guía en este punto a H. S. Versnel, Inconsistencies in Greek and Roman religion II, Transition and reversal in myth and ritual (Leiden - New York - Köln 1993) 48 ss. 
tarea, al narrarse en él los rituales de la iniciación, así como por el ya comentado papel sincrético de Isis. Lo que, repetimos, no ocurre en absoluto en las novelas griegas, donde sólo cabía el recurso a las exégesis ingeniosas.

Y la tercera cuestión es la referida a la alegoría como herramienta no sólo expresiva o poética sino interpretativa y que fue muy utilizada por los filósofos estoicos, la escuela más citada siempre que se habla del simbolismo de las artes plásticas y la literatura. Pues bien, nadie discute que la alegoría fue un método muy frecuentado en el s. II d. C., es decir, el momento central de la producción novelesca griega. Pero a su vez ha sido replanteada como metodología exegética por la corriente que estudiamos, en la medida en que uno de sus postulados básicos (véase después una cita concreta al respecto) es que un texto literario puede ofrecer dos niveles, uno, el aparente, con el que se queda el lector no preparado para una interpretación profunda, y aquel que sólo puede conocerse y apreciarse si se acepta la alegoría como medio apropiado. Es más, Merkelbach, por ejemplo, está convencido no sólo de que Homero y la tragedia tienen un fondo religioso, sino de que una buena parte de la antigua literatura, en particular la poesía, contiene ya manifestaciones alegóricas. Por ello no sorprende que en alguna ocasión se haya tildado a un autor como Merkelbach de alegorista en el sentido de compararlo con los alegoristas homéricos estudiados en un conocido libro por $\mathrm{F}$. Buffière $^{16}$, una calificación que en este caso iba acompañada de críticas acerca de "les abus de cette méthode" y de "interprétations abusives" (p. 359), para concluir que "cet essai d'interprétation n'est, à tout prendre, qu'un roman de plus, écrit avec talent et qui serait convaincant, si l'on n'avait un certain souci de la rigueur dans les démonstrations" (p. 360). Y es que esta separación en dos niveles es esencial para la perspectiva alegórica pero puede llevar, como veremos con algunos ejemplos, a extremos sorprendentes. Y suele tener como secuela el ya citado contagio, en el sentido de que, si se parte de una determinada obra en la que existen argumentos para la aplicación del método alegórico, es una especie de compulsión la que fuerza a desplegar los mismos principios en otros textos en los que ya no se dan esos elementos objetivos citados. Porque difícilmente puede explicarse de otro modo el salto que supone pasar de las Metamorfosis de Apuleyo, con su explicitación en el terreno de la religiosidad, a los textos griegos, en los que no existe una explicitación semejante. Y nadie discutirá, creemos, que no se trata de dos ámbitos nítidamente separados por esa diferencia. Una diferencia que sólo se puede soslayar si se cree, puesto que de creer se trata, en la validez del método alegórico para penetrar en unas reales o supuestas claves.

En esta corriente el peso de las pruebas suele recaer en una rica casuística, de modo que, sobre todo en un género forjado sobre la base de motivos y episodios repetitivos, el lector se ve obligado a releer continua y atentamente los textos griegos para aceptar o descartar tantas afirmaciones. Y esto puede, en efecto,

${ }^{16}$ Así, J. Defradas, en su reseña del libro de Merkelbach de 1962 en REG 77 (1964) 357-360 (p. 357). 
llegar a minucias que a veces hacen sonreír: así, por citar un solo pero muy significativo ejemplo tomado del libro de Kerényi, la caída de Dafnis en la trampa para lobos en Longo (1.12) se nos dice que no es sino una representación literaria de un "entierro" mistérico (p. 141). Y todavía un seguidor fiel de esta corriente como es el citado Witt, estudioso de la religiosidad y la filosofía del tiempo, nos hace saber ${ }^{17}$ no sólo que "Xenophon is not just a story-teller. He has a didactic and indeed a religious aim. His tale is that of the salvation of human lives through faith in divine powers that do intervene" y que la Isis invocada en las Efesíacas es la proclamada por Plutarco, sino que "just as in the New Testament the purpose is to set forth the Gospel..., so in the literature of Isiacism of which the Ephesiaca is a fair specimen the implied aim is to prove the redemptive power of faith" (p. 253), de suerte que (ahora entramos en un precioso detalle), por ejemplo, la estancia de Habrócomes en casa del pescador Egialeo tiene su propio simbolismo, puesto que, entre otros pormenores significativos, está incluida la profesión del anciano: "For the faithful follower of Isis the fish is taken out of the water just as the initiate is removed from the water in which he has been ceremonially dipped" ( $p$. 250). Tal insistencia en los detalles, si no nos acorazamos con una vigilancia crítica y continua, puede dar lugar a la falsa impresión de que tantos sumandos ofrecen un resultado al menos relativamente convincente. Pero la conclusión, una vez adoptada la adecuada perspectiva, es que esa casuística no es difícilmente desmontable, en especial si se utiliza la lógica y el sentido común, además y sobre todo si no olvidamos que cuando leemos estas novelas estamos leyendo ficción con una larga tradición como respaldo. Es más, aparte de las numerosas críticas que provocaron las publicaciones de los autores que aquí nos importan, no ha de olvidarse que se han hecho excelentes estudios de las diversas novelas griegas y sobre una muy variada temática, incluso de sus aspectos religiosos, sin el menor recurso al supuesto trasfondo iniciático-mistérico defendido por la corriente de la que Merkelbach es el principal referente. Un hecho que nunca seguramente hubiera podido suceder de haber tenido esta doctrina una determinante porción de veracidad. Lo que significa, en nuestra opinión, que tal doctrina no se nos ofrece como una alternativa exegética sin la que es difícil acceder a una cabal comprensión del mundo representado por estos relatos.

Pero a nosotros sí nos parece un problema de primera magnitud, por lo cual queremos incidir en esta cuestión, que por lo general en esa corriente de estudiosos se desdeñe, en mayor o menor grado, la tradición cultural y literaria griega. Y esto en una época en la que escritores y lectores dependían como nunca antes de esa herencia. Sin que hubiese incompatibilidad alguna, como vemos muy en particular en Plutarco, entre el mantenimiento vivo de esa tradición, entendida eficazmente como una formativa paideia, y las nuevas tendencias ideológicas, entre

${ }^{17}$ En el capítulo XVIII de su libro Isis in the Graeco-Roman World (Ithaca 1971) dedicado al "Xenophon' Isiac romance". 
ellas y con enorme energía, las religiosas con sus poderosos componentes de origen oriental.

$\mathrm{Y}$ es que, efectivamente, una conducta que acompaña de un modo casi forzoso esta tendencia interpretativa es la escasa o nula importancia que se le concede a los textos novelescos como obras literarias. En primer lugar, puesto que no pueden importar mucho las cualidades que hacen que un texto se inserte en un género y en una tradición artística, por cuanto se trata de indagar en él casi exclusivamente la existencia de supuestas pruebas que permitan situarlo dentro del ámbito deseado. Esto explica, en segundo lugar, la diferencia esencial que se da entre los demás intentos de descubrir los orígenes del género novelesco y el defendido por Kerényi, Merkelbach y otros, para los que sólo es relevante el papel que juega en él la alegoría y los datos pretendidamente reveladores de creencias y ritos mistéricos. De modo que, si revisamos la nómina de los principales representantes de esta corriente, no nos sorprende que prácticamente todos ellos procedan del ámbito de la historia de las religiones y la filosofía o simplemente del campo historiográfico, no del filológico. Y las consecuencias son las esperables desde el momento en que las novelas no son contempladas básicamente como textos literarios, sino como un aprovechable almacén de supuestas referencias religiosas, dejándose de lado la historia literaria griega y los conceptos de inspiración y emulación. Y basta poner unos pocos ejemplos referidos a ciertos motivos recurrentes en el ámbito literario. Uno, apreciable por su uso tanto en la literatura como en el folclore y desde luego de gran antigüedad, es el conocido, por su presencia también en la Biblia, como el de "la mujer de Putifar", pero que es despojado por Merkelbach de su propio valor como tal al convertirse simple y exclusivamente en un referente religioso: "Das Motiv von Potiphars Weib ist uns schon im Mythos des BataOsiris und in der Geschichte vom klugen Arzt begegnet. Wie schon oben angedeutet, ist die Episode wahrscheinlich im Mysterium gespielt worden"18. Un segundo ejemplo muestra igualmente la distancia establecida entre la literatura como tal, de un lado, y la literatura como mera envoltura de una expresión religiosa, de otro, sobre todo tal como está contundentemente trazada por Merkelbach. Éste en su artículo ya citado de 1959 y refiriéndose en concreto, en el relato de Longo, a los $\gamma v \omega p i ́ \sigma \mu \alpha \tau \alpha$ depositados con Dafnis reconoce, como no podía por menos, que tales signa aparecen ya en la comedia y la tragedia, pero que mientras en éstas son sólo "literarische Motive", en cambio "bei Longus beziehen sie auf ein Initiationsritual" (p. 60). Y de nuevo en su libro de 1962 (p. 219) leemos sobre estos "Erkennungszeichen": "Man meint zunächst, dies wäre ein Motiv aus der neuen Komödie. Aber es ist ein Ritual". Son

${ }^{18}$ Roman und Mysterium in der Antike (München - Berlin 1962) 99. Cf. también pp. 82 y 99. En p. 273 leemos respecto al episodio correspondiente de Ársace en Heliodoro: "Es folgt eine Episode, welche der Versuchung des Joseph durch Potiphars Weib, des Bata durch die Frau des Anubis entspricht. In Syrien hat es eine ähnliche Sage von Kombabos und Stratonike gegeben (Ps. Lukian, De dea Syria 23/5)". La tradición griega, en cambio y como comprobamos, es tenida por irrelevante. 
los objetos que porta el mystes en el rito y que permiten reconocerlo como tal; de ahí que con Dafnis sean depositados unos signa que permitirán más tarde reconocerlo como legítimo "Sohn des Dionysophanes (=Dionysos)". Con lo que, una vez más, la tradición literaria pasa a un segundo plano a favor de una alternativa tenida por verdad absoluta.

$\mathrm{Si}$ en un tercer ejemplo nos detendremos más es porque atañe a un punto esencial del género novelesco. Nos referimos al de la pasividad usual del héroe ${ }^{19}$ que no puede ser naturalmente sino un trasunto de la del mystes, como ya señalara Kerényi (p. 127), lo que fue lógicamente aplaudido por Merkelbach (1962, p. 143), que apela a su vez al concepto de la "Passivität des Mysten" con bastante frecuencia. Así, en la situación en la que, en el texto de Aquiles Tacio, Clitofonte es agredido por Tersandro (5.23.5 ss.; cf. también 7.14.3), es perfecto y coherente que el primero diga que todo aquello era "como en un misterio" (ळ̋ $\sigma \pi \varepsilon \rho \dot{\varepsilon} v$ $\mu v \sigma \tau \eta \rho i ́(\omega)$, lo que no es sino extremadamente significativo para la exégesis que nos ocupa, sólo que se pasa por alto el pequeño detalle de que el narrador y protagonista no está refiriéndose precisamente al tema de su pasividad sino a su total ignorancia de lo que le está pasando, lo que no es a su vez sino un tópico referido al secretismo mistérico ${ }^{20}$. Y es el temor a que le pueda sobrevenir algo peor que una paliza lo que le impide intentar una mínima defensa, no la emulación alegórica del iniciando en las ceremonias rituales. Los casos citables en la misma línea son muy numerosos y todos ellos han sido comentados en idéntico sentido: así, que Dafnis en Longo no reaccione ante la violencia de los metimnenses no puede sino responder a las mismas razones que la conducta de Clitofonte, y no digamos la pasiva actitud de Habrócomes, en Jenofonte de Éfeso (el texto no alude al silencio), ante el gobernador de Egipto en 4.2.2, cuando se puede entender como provocada, según está explicitado en el texto, por su desánimo (àđò $\mu \grave{\varepsilon} v \tau \tilde{\omega} v \kappa \alpha \kappa \tilde{o} v$ $\dot{\alpha} \chi \alpha v \grave{\eta} \varsigma \tilde{\eta} v)$ y la idea de que Antía está muerta y no precisamente porque refleje, una vez más según Merkelbach (1962, p. 104), la pasividad ritual del iniciando ${ }^{21}$.

Y, por lo demás, también en este tema, como en tantos otros, aparte de leer muy por encima el texto griego y concediendo mínima importancia al contexto, se deja limpiamente de lado el proceso evolutivo del héroe en la literatura griega

\footnotetext{
${ }^{19}$ Muy tratado en los estudios sobre la novela, dada su importancia. Entre las muchas referencias elegimos ésta de T. Hägg (The novel in antiquity [Oxford, 1983]) que atañe especialmente a los protagonistas masculinos: "The novels lack true heroes. The principal male characters are pale marionettes, who passively let themselves be tossed about the world by Fortune and are always on the defensive in the face of superior rivals and active women" (p. 210). Los protagonistas femeninos responden por lo general a una variedad mayor de actitudes, sobre todo en ciertas situaciones.

${ }^{20} \mathrm{Si}$ se desea, el pasaje puede calificarse incluso de humorístico. Así lo entiende M. Berti en su muy crítico artículo "Sulla interpretazione mistica del romanzo di Longo", SCO 16 (1967) 343-358: "Mi sembra non tanto la conferma del possibile significato mistico di questo episodio, quanto una battuta, che Achille Tazio attribuisce a Clitofonte e che sottolinea la comicità della situazione" (p. 352).

${ }^{21}$ Esa conducta de Habrócomes y por razones parecidas es la que le hace ceder eventualmente en 3.12.4 a los requerimientos amorosos de Cino.
} 
y que, además del hecho evidente de que ya en la Odisea el protagonista tiene unos rasgos distantes del canon de la heroicidad de la Ilíada, con la tragedia del siglo V y la típica $\alpha \mu \eta \chi \alpha v_{i}$ í del Jasón de Apolonio de Rodas ${ }^{22}$ es explicable que se haya dado lugar, con diversos matices, a este tipo relativamente pasivo y nada heroico que encontramos en las novelas. Sin que tengamos que añadir que en los argumentos novelescos no se trata de una actitud referida sólo a momentos concretos, según parecen juzgar los estudiosos citados, sino un rasgo constitutivo del tipo. Y por ello mismo ha sido estudiado desde otros puntos de vista más internos y desde luego más literarios, si bien con conclusiones que no tienen por qué ser siempre del todo convincentes, lo que no significa en absoluto que se haya de apelar a la solución propuesta por Kerényi y Merkelbach. Así, ya M. D. Muchow ${ }^{23}$ ha insistido en una postura bastante cercana a la posterior de D. Konstan y centrándose en los casos de Jenofonte de Éfeso, Caritón y Heliodoro, en que la pasividad está relacionada con el erotismo, puesto que se da ya en el momento mismo del enamoramiento (Clitofonte en Aquiles Tacio es una excepción señalada), con un estado de postración en vez de actuar para satisfacer sus deseos, y de ahí que sean otros personajes los que deban descubrir las causas de ese estado e intervenir para lograr esos fines. Y con una propuesta muy arriesgada, para Muchow (que se remonta a las doctrinas de M. Foucault) se trata por parte de los novelistas de valorizar la pasión personal frente a los matrimonios impuestos, de modo que la pasividad (o, lo que es lo mismo, el ser percibidos como víctimas) resultaría ser un modo de escapar a la culpa convencionalmente ligada a la pasión personal frente al uso social. Al ser pasiva su conducta, esa pasión no sería percibida como una forma de rebeldía frente a la convención social.

En cuanto a Konstan, afirma en un libro muy conocido ${ }^{24}$ que "the relatively passive nature of the novelistic hero... is a function of the equivalence of the male and female roles in the central love plot of the narrative, which leaves no room for valiant rescues in which the male lover can act out an epic gest" (p. 30), lo cual debería matizarse, puesto que no faltan en estos relatos ni las búsquedas de la heroína por parte del héroe ni episodios en los que éste muestra cierto nivel de decisión $^{25}$. Y no debe olvidarse que, lejos del canon heroico, el protagonista novelesco

${ }^{22}$ Cf. G. Lawall, "Jason as an anti-hero", YCS 19 (1966) 119-169, y Ch. Cusset, "Le Jason d'Apollonios de Rhodes un personnage romanesque?", en B. Pouderon (ed.), Les personnages du roman grec. Actes du Colloque de Tours, 18-20 novembre 1999 (Lyon 2001) 207-218, con una respuesta positiva a esa pregunta. El tema de la evolución del héroe griego ha sido tratado en un valioso compendio por C. García Gual en su Los orígenes de la novela (Madrid 1972) 117-132.

${ }^{23}$ Passionate love and respectable society in three Greek novels (Ph.D. Diss. Johns Hopkins University 1988).

${ }^{24}$ Sexual symmetry: Love in the ancient novel and related genres (Princeton 1994).

${ }^{25}$ Quéreas se convierte en un caudillo, Teágenes actúa como un atleta. "Si l'on peut reprocher aux héros romanesques grecs d'être plus réactifs qu'actifs, il n'empêche que le roman ouvre parfois le champ à l'expression d'une réelle force de caractère, qui modifie l'appréciation première du personnage": Así $R$. Brethes, "Clitophon ou une anthologie de l'anti-héros", en B. Pouderon (ed.), Les personnages du roman grec ya citado, 181-191 (p. 184). 
responde a un ideal relativamente nuevo, en el que se suman el alto nivel social, la belleza, la concentración precisamente en el amor como vocación exclusiva ${ }^{26}$ y esa conducta que se expresa justamente como una estoica pasividad demostrada en duras pruebas en el curso de las obligadas peripecias.

Es instructivo, por otra parte, observar el orden mismo de las publicaciones más relevantes de la corriente interpretativa que estudiamos. Después del libro de Kerényi y su secuela en los de Altheim, ya citados, la irrupción de Merkelbach, decisiva para el despliegue del tema, incidió primero, como hemos mencionado también y como hubiera debido ser de esperar, en la novela de Apuleyo (1953) y desde luego en las secciones del texto, es importante subrayarlo, que se apartan decididamente del Asno griego. Pero el paso siguiente, de acuerdo con el típico y ya señalado expansionismo o contagio de esta corriente, fue ya la aplicación a las novelas griegas, si bien de un modo más particular a la de Longo. En poco tiempo se suceden dos artículos, uno ya citado del propio Merkelbach (1959) y otro de Chalk $^{27}$, en los que la atención se concentra ya en Longo, hasta 1962, la fecha en que se publica el libro más destacado del primero y que también hemos mencionado, con la extensión a todo el género en griego salvo Caritón (véase más adelante), pero donde Longo sigue ocupando un lugar de cierto privilegio ${ }^{28}$. Y, más tarde, Merkelbach volverá igualmente a reiterar sus tesis y a ocuparse nuevamente de Longo ${ }^{29}$. Sin que pueda hablarse estrictamente de una escuela, pero con clara continuidad entre sus principales representantes, las ideas de estos autores alcanzaron pronto un gran eco, un eco que, como comprobaremos en la continuación de este artículo, todavía hoy resuena. Pero en las críticas, que no faltaron en absoluto, se les señalaron no ya sólo otras posibilidades interpretativas más razonables sino fallos metodológicos graves. No obstante, había una suficiente coherencia entre esas publicaciones citadas, en el sentido incluso de un mutuo apoyo, lo que prestaba a sus ideas una aureola de solvencia. Así, por ejemplo y como

${ }^{26}$ Un antecedente que debe ser tenido muy en cuenta para este paso al primer plano del erotismo en una narración está a todas luces en Apolonio de Rodas, cuyo texto es poco sospechoso de tener significados místicos. Véanse, con inclusión de los precedentes que llevan a la nueva situación, nuestros estudios "El amor, de la Comedia Nueva a la novela”, en M. Brioso Sánchez y A. Villarrubia Medina (eds.), Consideraciones en torno al amor en la literatura de la Grecia antigua (Sevilla 2000) 145-229, y "El concepto del amor en Grecia: entre el siglo IV a.C. y el Cristianismo", en A. Pérez Jiménez y M. C. Salcedo Parrondo (eds.), Las alas del placer. Las riberas del Mediterráneo bajo las flechas de Eros (Madrid-Málaga 2004) 83-127.

27 "Eros and the Lesbian Pastorals of Longos", JHS 80 (1960) 32-51. Este artículo, que sepamos, tuvo dos reimpresiones en volúmenes colectivos, en 1984 y 1986, lo que nos permite sospechar que su autor mantuvo sus tesis a pesar de las graves objeciones suscitadas y que el artículo mismo tuvo una acogida profundamente interesada.

${ }^{28}$ En esta corriente también debemos situar, aunque su horizonte sea mucho más limitado, la monografía Daphnis (Meisenheim am Glan 1969) de G. Wojaczek.

${ }^{29}$ Die Hirten des Dionysos. Die Dionysos-Mysterien der römischen Kaiserzeit und der bukolische Roman des Longus (Stuttgart 1988). Véanse sobre todo pp. 135-204. De hecho, el largo apartado dedicado a Longo no es sino una especie de corolario del grueso del volumen, centrado en las creencias y el culto dionisiaco. 
ya señalara, por si hubiera hecho falta, el propio Chalk en su reseña del libro de Merkelbach de $1962^{30}$ lo esencial de las tesis de éste está ya en el de Kerényi de 1927 (p. 163), y, añadamos como confirmación, que ciertamente en la lectura de las páginas de Merkelbach no sólo encontramos a cada paso citas de aquél, casi como en un continuo homenaje a su principal antecesor, sino que lo juzga como el único investigador que hasta la fecha había tenido una idea acertada sobre el origen de la novela ${ }^{31}$. De modo que, si se ha hablado a veces de la pertinacia de Merkelbach, que bastante después de haber recibido una lluvia de críticas, volvió a ofrecernos una nueva y densa publicación sobre el tema (1988), aunque esta vez centrándose más, como hemos dicho, en el texto de Longo ${ }^{32}$, no es ajeno a esa actitud el que no faltara ese eco que hemos subrayado. Las críticas, algunas muy duras y con frecuencia certeras, no fueron suficientes ni tan persuasivas siempre como para que en la perspectiva de otros estudiosos no dejase de percibirse, aun entre errores, una cierta respetabilidad en la exposición de esas ideas. Por otra parte, para muchos era sin duda de agradecer que, después de la magistral obra de Rohde, en la que sin embargo podía detectarse cierta incomprensión ante el género y muy especialmente respecto al relato de Longo, apareciese, dentro desde luego del debate sobre el origen del género, una dimensión relativamente nueva que podía contribuir a realzar el papel de este advenedizo en la historia literaria greco-romana. El propio Merkelbach no dejó de expresar su sorpresa ${ }^{33}$ ante la posición de Rohde: no podía entender que precisamente un entendido en la materia de la religiosidad griega no lograse captar el sentido profundo de estas novelas. Y es que, además y también como apoyo de su postura, para él era esencial el hecho, ya señalado, de que la historia literaria griega desde sus textos más antiguos estaba sustentada precisamente en la religión ${ }^{34}$. Por ello no debe sorprender que, ante el grave problema que representaba para su interpretación de Longo la relevante parte que desempeña en ella la influencia de la poesía bucólica, Merkelbach en una acrobacia muy típica de su metodología llegara a preguntarse en su artículo de 1959 si los propios poemas bucólicos de Teócrito no eran ya sino

${ }^{30}$ CR N. S. 13 (1963) 161-163.

${ }^{31}$ En su Vorwort leemos: "Die Entstehung des antiken Romans glaubten die Gelehrten -mit Ausnahme von Karl Kerényi- anders erklären zu können”. Y en otros lugares confirma esta relación: así, en ese mismo primer libro (p. 89): "Unsere Untersuchungen aber haben Kerényis Darlegungen in unerwartetem Ausmaß bestätigt”. Sus referencias al más reciente libro de Altheim -de 1948 y sólo a éste-son, en cambio, mucho menos numerosas y muy puntuales.

${ }^{32}$ Todavía unos años después Merkelbach nos ofrecía un aspecto nuevo de sus doctrinas en "Novel and Aretalogy", en J. Tatum, (ed.) The Search for the Ancient Novel (Baltimore 1994) 283-295, un artículo del que nos ocuparemos en II. Respecto al talante con que Merkelbach recibió las críticas, no nos resistimos a citar un pasaje de Die Hirten des Dionysos donde, después de recordar los nombres de oponentes como R. Turcan y A. Geyer, escribe: "Ich gebe keine Antikritik zu diesen Ausführungen, denn diese Autoren bestreiten nich, daß der Roman des Longus dionysisch ist", además de otras breves observaciones que no nos parecen sino subterfugios (p. 137, n. 4).

${ }^{33}$ Véase en el libro de 1962 la sugestiva n. 3 de p. 89.

${ }^{34}$ En el Vorwort ya mencionado del libro de 1962 leemos esta primera frase discutible o, si se quiere, matizable en todos sus extremos: "Epos, Lyrik und Drama haben ihren Ursprung in der Religion". 
una expresión dionisiaca, como, para él, lo era la novela de Longo (p. 59), y que en su libro de 1962 (p. 205, n. 3) atribuyera a Teócrito la pertenencia al círculo de poetas dionisiacos de Cos fundado por Filetas. Es más, en la misma obra (p. 222, n. 6) se pregunta también si ya para Teócrito Dafnis fue "der Exponent eines Dionysoskultes unter der Sizilischen Hirten".

La mención de Teócrito nos lleva, brevemente desde luego, a establecer un cierto paralelismo, salvadas todas las distancias, con lo ocurrido con Longo en el ámbito que nos ocupa. No hace falta recordar que, en el caso de la poesía bucólica y con el apoyo de ciertas informaciones contenidas en los escolios, hubo también una hipótesis, propuesta por R. Reitzenstein ${ }^{35}$ acerca del supuesto origen del género en un thíasos que imitaría la previa existencia de unos ßovкódor como iniciandos del culto dionisiaco ${ }^{36}$. Tendríamos también en este otro género tan novedoso $^{37}$ un supuesto origen ritual, pero que, alejado por igual de los antecedentes literarios, igualmente ofrece flancos muy débiles a la investigación. Y, si queremos apurar también muy concisamente un aspecto en el que una y otra hipótesis, la que atañe a las novelas y la que se refiere al género bucólico, se encuentran con un problema común, podemos recordar que ya uno de los reseñantes del libro de Kerényi, A. D. Nock, escribió que éste no podía explicar la amplia distancia temporal y los pasos entre los ritos iniciáticos egipcios originales y la profunda reelaboración literaria que, supuestamente, se daría en las novelas: "We should assume several missing stages of development to permit of the disappearance of the form"38. Lo que se ha dicho también como objeción respecto a las ideas expuestas por Reitzenstein por parte de un especialista en el ámbito de la poesía bucólica, T. G. Rosenmeyer, quien ha escrito en un conocido libro: "If the pastoral does have ritual roots, we know nothing about the stages of transition from the situation pictured in the scholia to the finished product" ${ }^{39}$.

\footnotetext{
${ }^{35}$ Epigram und Skolion. Ein Beitrag zur Geschichte der alexandrinischen Dichtung (Giessen 1893). Véase una breve pero clara exposición sobre este tema en M. García Teijeiro, "Notas sobre poesía bucólica griega", CFC 4 (1972) 403-425, en especial 405-407. García Teijeiro señala el escaso eco de esta propuesta con la única cita del mitólogo húngaro y estudioso de las religiones Trencsényi-Waldapfel, quien todavía en 1966 trató de recuperarla (pero véase nuestra nota siguiente). Y recuérdese que Reitzenstein publicó en diversas ocasiones trabajos sobre Apuleyo y las religiones mistéricas.

${ }^{36}$ Merkelbach ya en su artículo de 1959 se hace eco de esta hipótesis: "Vermutlich hat Theokrit

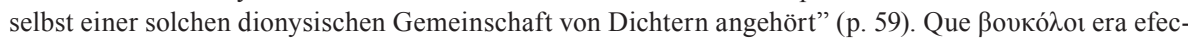
tivamente el nombre que se daban los iniciandos nos lo recuerda ahí el propio Merkelbach (p. 48).

${ }^{37}$ El único creado en el Helenismo y con rápido y notable éxito. No cabe duda de que, aparte de la incógnita de su origen, fomentada por las oscuras informaciones que se leen en los escolios, el $\mathrm{id}$. VII con su enigmática atmósfera y la misteriosa y debatida figura de Lícidas contribuyó eficazmente a los interrogantes a los que pretendió responder la hipótesis de Reitzenstein. Más adelante (en II) tendremos ocasión de subrayar el cierto paralelismo que, de nuevo salvadas todas las diferencias, existe también entre Lícidas y otra aparentemente enigmática figura de Longo, Dionisófanes.

${ }^{38}$ Gnomon 4.9 (1928) 485-492 (p. 485). Y de nuevo igualmente: "There remains the necessity of supposing a number of lost missing links" (p. 489).

${ }^{39}$ The Green Cabinet. Theocritus and the European Pastoral Lyric (Berkeley - Los Angeles - London 1969), p. 34.
} 
Hemos recordado anteriormente que en determinado momento esta doctrina supuso una propuesta global, de modo que, en el caso griego, podían extraerse citas y argumentos de cualesquiera textos novelescos ${ }^{40}$, incluidos los fragmentos y los resúmenes bizantinos. Pero a las dificultades que implicaba la aplicación de una misma hipótesis a todo un género se sumaba naturalmente la de que éste, aun con sus pocos representantes, conlleva, y nos referimos ahora en particular al ámbito griego, una profunda evolución y que en él convergen tradiciones literarias e ideológicas diferentes. Y una prueba de ello y a su vez también de que la metodología empleada no podía ser muy estricta es que ya Merkelbach tuvo insalvables dificultades en la aceptación de Quéreas y Calírroe de Caritón entre las obras a las que aplicar sus criterios exegéticos. Éste es un punto que no suele destacarse en las discusiones sobre el tema, pero que nos parece muy relevante, sobre todo porque muestra que la pretendida uniformidad en el género novelesco no es tal en cuanto se profundiza en su problemática y no nos quedamos en sólo los rasgos comunes. Pero en ningún momento, que sepamos, explicó en detalle el estudioso alemán las razones que lo llevaban a excluir de su materia prima una novela que había sido aceptada como tal sin mayores problemas por su mentor Kerényi ${ }^{41}$ y sólo tenemos las referencias que hace en su Roman und Mysterium y de las que ofrecemos algunas. De hecho, Caritón ni siquiera figura en su índice temático y ya desde su primera mención (p. 89) no es sino como tal excepción, lo que sólo se justifica más tarde muy de pasada y de modo dudoso: "Dieser Autor hatte ein allgemeines Empfinden für den religiösen Wert des Romans, aber der mystische Sinn der Einzelnen Episoden war ihm nicht bekannt. Auf Schritt und Tritt widerspricht seine Erzählung dem Sinn, welchen die Episoden nach der Mysteriendeutung haben sollten" (p. 159). Por nuestra parte, confesamos que nos hubiera gustado conocer, por ejemplo, por qué la muerte aparente de Calírroe, que supone un episodio de gran importancia entre las peripecias de la novela, no puede ser catalogada entre los hechos paralelos de otras que, según Kerényi y Merkelbach, sí son expresivos de ese origen mistérico ${ }^{42}$. Lo más a que llega Merkelbach es a preguntarse y responderse, resumiendo insistentemente una, para él, difícil (y desasosegante) cuestión: "Welche Möglichkeiten einem vom Kult getrennten Liebesroman offenstanden, zeigt das Werk des Chariton. Dieser Autor hat zwar eine vage Idee von der religiösen Beziehung eines Romans gehabt; aber die wirkliche Mysterienbedeutung der verschiedenen Episoden, welche im Roman

\footnotetext{
${ }^{40}$ Por lo que atañe a las novelas latinas, todavía Kerényi se refiere en su libro también a la Historia Apollonii regis Tyri e incluso en alguna ocasión al Satiricón. Merkelbach en 1962 dedica un apartado a la Historia Apollonii, pero alude al Satiricón sólo como texto paródico de la novela erótica.

${ }^{41} \mathrm{Cf}$. de su libro citado pp. 11 s., como luego sobre Quéreas p. 35.

${ }^{42}$ Pero, para comprobar que Caritón no habría sido tan ajeno al tema, véase lo que escribe Merkelbach (p. 166, n. 6), al tratar de los cenotafios y por tanto de las falsas muertes: "Nach Plut. De Iside 18 hat Isis in Ägypten eine ganze Anzahl Kenotaphien errichtet. Chariton IV 1 hat einen verlorenen Isisroman zum Vorbild, in dem die Romanheldin die feierliche Beisetzung eines Osirisbildes durch Isis nachvollzog. Aber Chariton hat den genauen Mysteriumsinn der Szene nicht gekannt und mehrfach Verkehrtes hereingebracht".
} 
traditionell waren, hat er nicht gekannt. Ständig stehen bei ihm solche Episoden in einem Zusammenhang, welcher dem Mysteriensinn entgegengesetzt ist. Darum ist die Lektüre des Chariton irritierend für einen Leser, der den geforderten Hintersinn kennt und erwartet" (p. 339). Y es especialmente con estas últimas palabras con las que las debilidades de su metodología saltan a la vista: si un representante tan relevante y tan antiguo (esto, es cierto, lo sabemos mejor ahora) del género como es la novela de Caritón no se ajusta (en realidad, como hemos comprobado, no se nos dice claramente por qué) a su sistema, para Merkelbach no es éste el que hace aguas, sino que la responsabilidad es del novelista y su obra (a este respecto) fallida. Y no se trata de una opinión aislada: también otro estudioso en la misma línea como $\mathrm{Chalk}^{43}$, del que pudiera haberse esperado una lectura más comprensiva o simpatética, incluso más entusiasta, de la monografía de Merkelbach, se limita a repetir acerca de Caritón lo mismo que ya afirmara el erudito alemán: que si se resiste a estas exégesis es porque, a pesar de su probable fecha, sería un caso excepcional de narrador no iniciado en los misterios, pero que habría imitado a los que sí lo eran (p. 162). Tendríamos así, y esto lo añadimos nosotros, una grave desviación en la tendencia alegórica del género y ya prácticamente en sus primeros pasos. Y, sin embargo, nadie duda de la religiosidad de Caritón, que no es precisamente comparable en su posición como escritor piadoso a un Aquiles Tacio, ni de que su relato siga un esquema bastante semejante a los de otras novelas, lo que, en cambio, no puede afirmarse sin muchas matizaciones en el caso concreto de Longo. Pero Caritón, como única excepción reseñable, carecería de lo que Merkelbach llamó un "doble fondo", o, con otras palabras, la caja de sorpresas que representan la propaganda y su consiguiente lección mistéricas ${ }^{44}$.

En suma, el resultado de la aplicación de estas doctrinas a los textos novelescos es usualmente y como seguiremos comprobando una lectura sesgada y muy parcial cuando no abusiva, con propensión a la ocurrencia analógica y a ensartar esas ocurrencias hasta constituir todo un sistema. De unos niveles más o menos convincentes, como es sobre todo el de Apuleyo, se pasa con arbitrariedad creciente a otros que pueden interpretarse con mucha mayor coherencia de otros modos y especialmente como componentes de obras de ficción sujetas a una tradición literaria. No obstante y ante todas estas evidencias, no han faltado después quienes ante tales teorías o sólo han aportado un juicio tibio, aceptando alguna que otra de esas propuestas y no el sistema entero, o, los más, han pasado simplemente del tema, dedicando su interés a otras cuestiones en torno a la novela,

\footnotetext{
${ }^{43}$ Precisamente en su citada reseña de Roman und Mysterium en CR N. S. 13 (1963).

44 "Es ist nämlich nicht allein das Werk des Apuleius ein Buch mit doppeltem Boden, vielmehr gilt dies für alle antiken Romanen, mit alleiniger Ausnahme des Chariton" (1962, p. 89, el subrayado es nuestro). En Die Hirten des Dionysos Merkelbach emplea otro término, pero el planteamiento es idéntico. Para él el problema de la comprensión moderna de una novela como la de Longo reside en que "man den gesamten Text auf zwei Ebenen interpretieren muß, auf der Ebene der Erzählung und auf der Ebene der dionysischen Zeremonien" (p. 138).
} 
o, los menos, se han dejado seducir por el brillo de esas exégesis. Pero otros estudiosos se opusieron radicalmente, ya fuese con reseñas, ya, en algunos casos, con artículos en los que podían ejercer, con un espacio suficiente, una censura más pormenorizada. Y han demostrado que hay muchos motivos para la defensa de la tesis contraria, que no es sino el reajuste que supone la vuelta a la básica consideración de las novelas griegas como textos literarios. Por nuestra parte, incidiremos en esta alternativa, con particular atención a Longo, en la continuación de estas páginas, donde también nos referiremos a algunos otros que, en cambio, se han empeñado en continuar en la misma senda de Kerényi, Merkelbach y Chalk sin que haya hecho mella en sus puntos de vista la oleada de críticas a que dieron lugar sus publicaciones. 